\title{
Metabolismo do ferro: uma revisão sobre os principais mecanismos envolvidos em sua homeostase
}

\section{Iron metabolism: an overview on the main mechanisms involved in its homeostasis}

Helena Z. W. Grotto

\section{Introdução}

\section{Metabolismo do ferro}

O ferro é um mineral vital para a homeostase celular. É essencial para o transporte de oxigênio, para a síntese de DNA e metabolismo energético. É um cofator importante para enzimas da cadeia respiratória mitocondrial e na fixação do nitrogênio. Nos mamíferos é utilizado principalmente na síntese da hemoglobina $(\mathrm{Hb})$ nos eritroblastos, da mioglobina nos músculos e dos citocromos no fígado. ${ }^{1} \mathrm{Um}$ indivíduo adulto tem no seu organismo de 4 a $5 \mathrm{~g}$ de ferro, sendo que cerca de 2,5 g na forma de $\mathrm{Hb}^{2,3}$

A deficiência de ferro acarretará conseqüências para todo o organismo, sendo a anemia a manifestação mais relevante. Por outro lado, o acúmulo ou excesso de ferro é extremamente nocivo para os tecidos, uma vez que o ferro livre promove a síntese de espécies reativas de oxigênio que são tóxicas e lesam proteínas, lípides e DNA. Portanto, é neces- sário que haja um perfeito equilíbrio no metabolismo do ferro, de modo que não haja falta ou excesso do mesmo. Essa homeostase vai possibilitar a manutenção das funções celulares essenciais e ao mesmo tempo evitar possíveis danos teciduais. Dentro da homeostase do ferro, os mecanismos de excreção são menos desenvolvidos e eficazes do que aqueles que regulam a absorção e distribuição, e nesses processos várias células, hormônios e proteínas transportadoras do ferro estão envolvidas., ${ }^{4,5}$

\section{Aquisição do ferro}

O ferro utilizado pelo organismo é obtido de duas fontes principais: da dieta e da reciclagem de hemácias senescentes.

Absorção intestinal (revisado em ${ }^{5,6}$ ).

De $1 \mathrm{mg}$ a $2 \mathrm{mg}$ de ferro são absorvidos por dia pelo epitélio duodenal, que apresenta estruturas vilosas para am-

Professor Associado do Departamento de Patologia Clínica da Faculdade de Ciências Médicas da Unicamp.

Departamento de Patologia Clínica da Faculdade de Ciências Médicas Universidade Estadual de Campinas -Unicamp - Campinas-SP.

Correspondência: Helena Zerlotti Wolf Grotto

Departamento de Patologia Clínica/FCM/Unicamp - CP 6111

13083-970 - Campinas-SP - Brasil

Fone 5519 35217064; Fax 551935219434

E-mail: grotto@fcm.unicamp.br 
pliar a superfície de absorção. Os precursores dos enterócitos encontram-se nas criptas, nas bases das vilosidades e, à medida que se diferenciam, migram para o ápice, onde têm uma vida média de um a dois dias quando, então, são naturalmente perdidos pela descamação do epitélio. ${ }^{3}$

A Figura 1 ilustra uma célula intestinal e a localização das proteínas envolvidas no processo de absorção. Uma dieta normal contém de 13 a $18 \mathrm{mg}$ de ferro, dos quais somente 1 a 2 mg serão absorvidos na forma inorgânica ou na forma heme. Alguns fatores favorecem a absorção intestinal, como a acidez e a presença de agentes solubilizantes, como açúcares. A quantidade de ferro absorvida é regulada pela necessidade do organismo. Assim, em situações em que há falta de ferro ou aumento da necessidade (gravidez, puberdade ou hemólise, por exemplo), há uma maior absorção de ferro. Para responder a essa maior demanda, há uma maior expressão das proteínas envolvidas nesse processo, como a proteína transportadora de metal divalente (DMT-1) e a ferroportina (FPT). A maior parte do ferro inorgânico está presente na forma $\mathrm{Fe}^{3+} \mathrm{e}$ é fornecida por vegetais e cereais. A aquisição do ferro da dieta na forma heme corresponde a $1 / 3$ do total e é proveniente da quebra da $\mathrm{Hb}$ e mioglobina contidas na

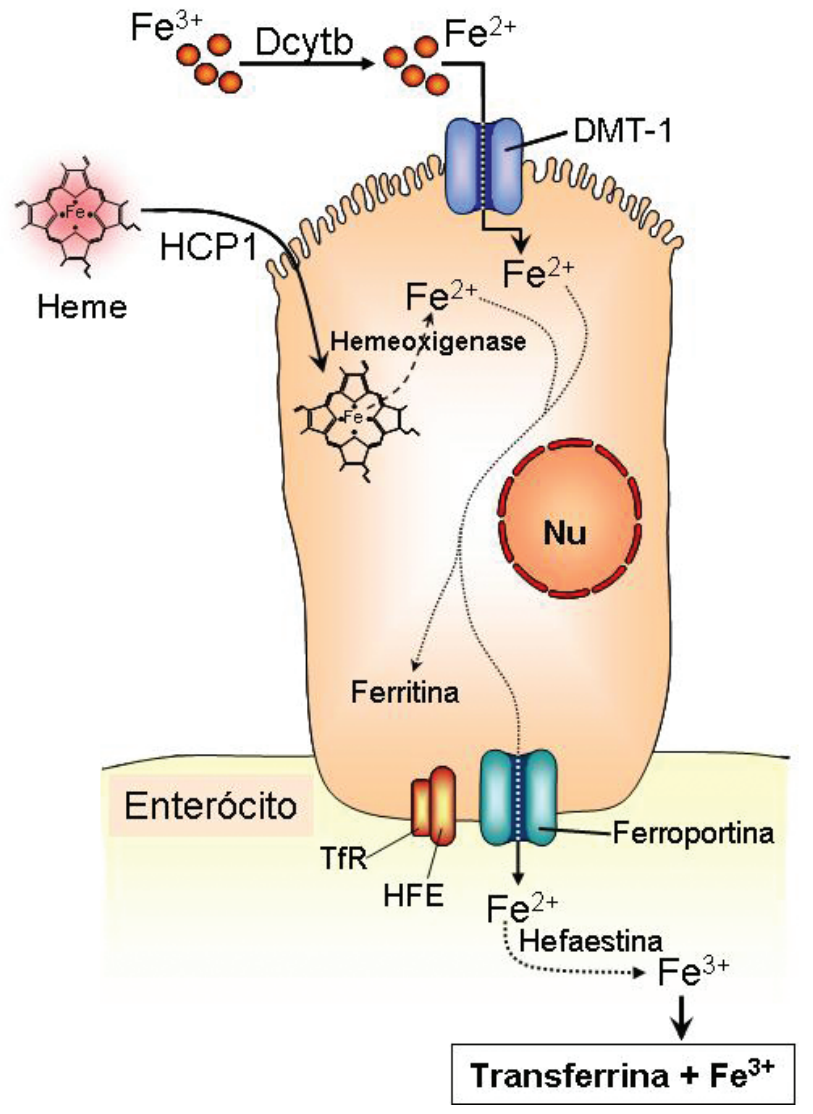

Figura 1. O enterócito e as proteínas envolvidas na absorção do ferro. Dcytb: ferroredutase; DMT-1: transportador de metal divalente-1; HCP-1: proteína transportadora do heme-1; Nu: núcleo; HFE: proteína da hemocromatose; TfR: receptor da transferrina carne vermelha. Ovos e laticínios fornecem menor quantidade dessa forma de ferro, que é melhor absorvida do que a forma inorgânica. ${ }^{2}$

ADMT-1, também conhecida como Nramp2, é composta por 12 segmentos transmembrana e, além do ferro, transporta $\mathrm{Mn}^{2+} \mathrm{Co}^{2+}, \mathrm{Cu}^{2+} \mathrm{e} \mathrm{Zn}^{2+}$. Em camundongos foi demonstrado que a substituição de uma glicina por arginina (G185R) no $4^{\circ}$ domínio transmembrana da DMT-1 está associada a um grave defeito na absorção do ferro intestinal, resultando em anemia microcítica. A utilização do ferro pelos precursores eritróides também está prejudicada. Para exercer sua função, a DMT-1 necessita que o ferro tenha sido convertido de $\mathrm{Fe}^{3+}$ para $\mathrm{Fe}^{2+}$, o que é mediado pela redutase citocromo b duodenal ou Dcytb. ${ }^{7}$ A internalização do ferro heme da dieta é feita pela proteína transportadora do heme-1 (HCP1), recentemente descrita e posicionada na membrana apical das células do duodeno. $\mathrm{O}$ heme liga-se à membrana da borda em escova dos enterócitos duodenais e a proteína transportadora de 50-kDa com nove domínios transmembrana atravessa intacta a membrana plasmática, importando o heme extracelular. A seguir o heme apresenta-se ligado à membrana de vesículas no citoplasma da célula. A HCP1 também é expressa em outros locais como o fígado e rins e sua regulação é feita de acordo com o nível de ferro intracelular: havendo deficiência de ferro, a HCP1 se redistribui do citoplasma para a membrana plasmática das células duodenais, enquanto em condições de excesso de ferro a redistribuição se dá a partir da borda em escova da célula para o seu citoplasma. Esse mecanismo regulador pós-tradução da proteína é interessante porque, de um lado, aproveita o heme da dieta antes que ele seja eliminado pelo peristaltismo do intestino e, no outro extremo, evita a captação desnecessária de ferro e o seu provável acúmulo. A hipóxia também induz a síntese da HCP1, facilitando a captação de heme quando há maior necessidade do organismo. ${ }^{8}$

No interior da célula, o ferro é liberado da protoporfirina pela heme oxigenase. Após o ferro ser liberado, fará parte do mesmo pool de ferro não heme, sendo armazenado na forma de ferritina ou liberado do enterócito para o sangue.

O principal exportador do ferro da célula para o plasma é a FPT, também conhecida como IREG1. Possui de 10 a 12 segmentos transmembrana e localiza-se na extremidade basolateral de vários tipos celulares, incluindo sinciciotrofloblastos placentários, enterócitos duodenais, hepatócitos e macrófagos. ${ }^{9}$ A expressão do mRNA da FPT está aumentada na deficiência de ferro e hipóxia. Como a DMT-1, a FPT também é seletiva para o ferro na forma $\mathrm{Fe}^{2+} .6,10$

Como a transferrina sérica tem grande afinidade pelo ferro na forma férrica, o $\mathrm{Fe}^{2+}$ externalizado pela FPT deve ser oxidado para $\mathrm{Fe}^{3+}$. A hefaestina, oxidase semelhante à ceruloplasmina sérica, é responsável por essa conversão. Mutações que inativam a FPT ou a hefaestina levam ao prejuízo na absorção e acúmulo de ferro no enterócito e nos macrófagos. 
A proteína da hemocromatose (HFE) está fortemente relacionada com a regulação da absorção intestinal do ferro. Interage com o receptor da transferrina (TfR) e detecta o seu grau de saturação, sinalizando para o enterócito se há maior ou menor necessidade de absorção do ferro na luz intestinal. Indivíduos com mutação no gene da HFE apresentam hemocromatose, caracterizada pelo acúmulo de ferro no organismo decorrente da contínua absorção do ferro pelo intestino (revisado em ${ }^{5,11,12}$ ).

\section{Reciclagem do ferro pelos macrófagos}

Como a maior parte do ferro no organismo está associada à molécula de $\mathrm{Hb}$, a fagocitose e degradação de hemácias senescentes representam uma fonte importante de ferro (de 25 a $30 \mathrm{mg} / \mathrm{dia}$ ). Essa quantidade de ferro reciclado é suficiente para manter a necessidade diária de ferro para a eritropoiese. ${ }^{3}$

Macrófagos do baço e da medula óssea e, em menor extensão, células de Küpffer no fígado reconhecem modificações bioquímicas na membrana da hemácia senescente. Essas alterações sinalizam para que o macrófago elimine essas células. Após a interação de receptores específicos nos macrófagos com as hemácias, inicia-se o processo de fagocitose, seguido da degradação dos componentes da hemácia. O catabolismo intracelular do heme envolve várias enzimas, como a NADPH-citocromo $\mathrm{C}$ redutase, a $\mathrm{HO}$ e a biliverdina redutase e terá como produtos o $\mathrm{CO}$, ferro e bilirrubina. A parte protéica da molécula de $\mathrm{Hb}$, a cadeia globínica, terá seus aminoácidos também reciclados e aproveitados na síntese de novas proteínas. $\mathrm{O} \mathrm{Fe}^{2+}$ pode ser estocado no próprio macrófago na forma de ferritina ou ser exportado pela FPT. Após a exportação pela FPT, o $\mathrm{Fe}^{2+}$ será oxidado pela ceruloplasmina, sintetizada no fígado. $\mathrm{O} \mathrm{Fe}^{3+}$ será transportado pela transferrina até os locais onde será reutilizado, predominantemente medula óssea, onde participará da hemoglobinização de novos eritrócitos. ${ }^{6,13}$

\section{Transporte e captação do ferro pelas células}

Como foi mencionado, o ferro é transportado no plasma pela transferrina (Tf), uma glicoproteína de $80 \mathrm{KDa}$ sintetizada e secretada pelo fígado, que possui dois sítios homólogos com alta afinidade pelo $\mathrm{Fe}^{3+}$. Além de solubilizar o ferro, a Tf atenua sua reatividade e facilita a sua liberação para as células. Em condições normais, a Tf plasmática tem a capacidade de transportar até $12 \mathrm{mg}$ de ferro, mas essa capacidade raramente é utilizada e, em geral, $3 \mathrm{mg}$ de ferro circulam ligado à Tf, ou seja, $30 \%$ da Tf está saturada com o ferro. Quando a capacidade de ligação da Tf está totalmente saturada, o ferro pode circular livremente pelo soro, na forma não ligada à Tf (NTBI), que é facilmente internalizada pela célula, contribuindo para o dano celular nos casos de sobrecarga de ferro. Quando complexado à Tf, a internalização do ferro é iniciada pela ligação desse complexo a um receptor específico (TfR) presente na superfície da maioria das células. ${ }^{14}$ Esse receptor é um homodímero transmembrana constituído de duas subunidades idênticas ligadas por pontes dissulfeto. Cada subunidade apresenta um domínio Cterminal extracelular, um domínio transmembrana e um pequeno domínio N-terminal citoplasmático. No domínio extracelular encontra-se o sítio de ligação para a molécula de Tf, enquanto no domínio citoplasmático, entre os domínios 20 e 23 , encontra-se a seqüência responsável pela endocitose do Tf complexado ao ferro. ${ }^{15}$

A afinidade do TfR à Tf diférrica parece ser determinada pela proteína produzida pelo gene da hemocromatose, a HFE, também presente na membrana plasmática dos eritroblastos. Dentro do citosol o HFE forma um complexo com o $\mathrm{TfR}$, reduzindo o número desses receptores sobre a membrana celular.

A interação Tf-TfR é facilitada pelo $\mathrm{pH}$ extracelular de 7,4 e a partir dessa ligação inicia-se o mecanismo de captação de ferro pela célula. O complexo Tf-TfR-HFE é internalizado por endocitose. Dentro do endossoma, a bomba de prótons dependente de ATP encarrega-se de reduzir o $\mathrm{pH}$, facilitando a liberação do ferro da Tf, que permanece ligado ao seu receptor e o complexo apoTf-TfR-HFE é reciclado de volta à superfície celular, quando então a apo-Tfé liberada do TfR. O ferro do endossoma atravessa a membrana da vesícula e alcança o citoplasma. ${ }^{3,16}$ A proteína DMT-1 é essencial para o efluxo do ferro do endossoma para o citoplasma. O ferro liberado pela Tf no endossoma está na forma férrica $\left(\mathrm{Fe}^{3+}\right)$ e a DMT-1 tem grande afinidade pelo $\mathrm{Fe}^{2+}$. Uma ferriredutase recentemente identificada e denominada Steap 3 é responsável pela redução do ferro liberado pela Tf, que será então transferido para o citosol pela DMT-1. ${ }^{17}$ A incorporação do ferro ao anel de protoporfirina irá formar o heme, que em combinação com as cadeias de globina formarão a molécula de $\mathrm{Hb}$.

Um produto da clivagem do TfR tecidual circula no plasma na forma solúvel do TfR (sTfR). A proteólise do TfR acontece próximo à $2^{\circ}$ ponte dissulfeto, na posição 100 da cadeia polipeptídica, numa ligação arginina-leucina. Ainda não está esclarecido em que local ocorre essa proteólise e qual protease estaria atuando no processo. O que já está bem documentado é a correlação direta entre a quantidade de sTfR circulante e a TfR celular. A forma solúvel do receptor que circula no plasma reflete a massa de TfR celular, $80 \%$ dela nas células da linhagem eritrocítica da medula óssea. Assim, a concentração de sTfR circulante é determinada primariamente pela atividade medular eritróide. Situações caracterizadas por hipoplasia da série vermelha, como anemia aplásica ou insuficiência renal crônica, apresentam níveis reduzidos de sTfR, enquanto condições com hiperplasia eritróide, como anemia falciforme ou outras anemias hemolíticas crônicas, estão associadas com níveis elevados de sTfR. ${ }^{18,19}$.

Outro fator que regula a expressão do TfR e, consequentemente, altera as concentrações circulantes do sTfR é o estado do ferro intracelular, mediado pelos elementos 
responsivos ao ferro (IRE) e as proteínas reguladoras do ferro (IRP), mecanismo que será discutido posteriormente. A deprivação de ferro favorece a formação do complexo IREIRP no mRNA do TfR, aumentando sua síntese. É o que pode ser observado em pacientes com anemia ferropriva que apresentam concentrações séricas elevadas de sTfR.

Um outro membro da família de TfR é o TfR2, bastante semelhante ao TfR descrito anteriormente, com $66 \%$ de similaridade na seqüência de aminoácidos, mas que se expressa predominantemente no fígado e em algumas linhagens celulares, como a K562 (eritroleucemia) e HepG2 (hepatoblastoma). Aparentemente, o TfR2 tem atividade de captação do ferro, mas, diferentemente do TfR, tem uma afinidade muito baixa (cerca de 25 vezes menor) pela Tf diférrica. ${ }^{20}$ Mutações no TfR2 têm sido descritas em pacientes com hemocromatose hereditária. ${ }^{21}$

\section{Transporte do ferro mitocondrial}

A mitocôndria é essencial para o metabolismo do ferro, já que é o único local onde ocorre a síntese do heme e a biossíntese dos clusters Fe-S. Ainda não está totalmente esclarecido como ocorre a entrada do ferro na mitocôndria. Em eritroblastos de murino foi descrito um transportador conhecido como mitoferrina (revisado $\mathrm{em}^{22}$ ).

Após o ferro ser transportado através da membrana mitocondrial, a frataxina, proteína localizada na membrana interna e na matriz mitocondrial, regula a utilização do ferro mitocondrial, destinando o ferro à síntese do heme ou à gênese dos clusters Fe-S (Figura 2). A frataxina tem um papel importante ao formar um complexo com o ferro porque previne a formação de radicais livres na mitocôndria. Assim, a falta de frataxina promove o acúmulo de ferro mitocondrial, em detrimento do ferro citosólico. Pacientes com ataxia de

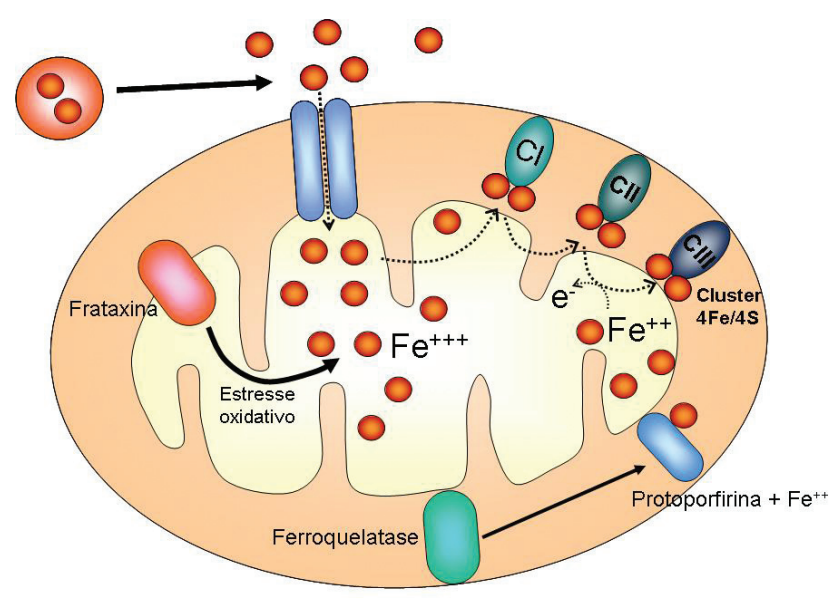

Figura 2. Internalização do ferro na mitocôndria e a regulação exercida pela frataxina na síntese do heme e dos "clusters" Fe-S. - A conversão do ferro férrico em ferroso é importante para que a ferroquelatase reconheça o ferro e o incorpore no anel pirrólico para formar o heme
Friedreich apresentam menor atividade de proteínas mitocondriais que contêm clusters Fe-S. A formação desses clusters é crítica para a prevenção do acúmulo do ferro e do stress oxidativo. Essa doença degenerativa autossômica recessiva é caracterizada por ataxia progressiva, perda sensorial e cardiomiopatia hipertrófica. ${ }^{23}$

A cadeia respiratória mitocondrial, com suas diversas subunidades envolvidas no transporte de elétrons, é importante na conversão do ferro férrico em ferroso, única forma química reconhecida pela ferroquelatase para ser incorporada ao anel pirrólico na finalização da síntese do heme. Mutações nas subunidades da cadeia respiratória mitocondrial têm sido reconhecidas como responsáveis por alguns tipos de anemias sideroblásticas adquiridas. Os transportadores responsáveis pela saída do heme da mitocôndria não estão bem definidos. Transportadores de membrana conhecidos como ABCB7 localizam-se na membrana interna da mitocôndria e exportam os clusters Fe-S para o citosol. Mutações no gene codificador do ABCB7 estão associadas com anemia sideroblástica ligada ao X com ataxia cerebelar e é caracterizada pelo acúmulo de ferro na mitocôndria (revisado $\left.\mathrm{em}^{24}\right)$.

\section{Estoque do ferro}

$\mathrm{O}$ ferro fica estocado nas células reticuloendoteliais do fígado, baço e medula óssea, nas formas de ferritina e hemossiderina. A apoferritina, a proteína livre do ferro, tem uma massa molecular de 46.000 Daltons e é composta de 24 subunidades que formam uma concha esférica. Esse núcleo central pode abrigar até 4.500 átomos de ferro na forma de hidroxifosfato férrico. A apoferritina contendo o núcleo férrico constitui a ferritina, a forma solúvel de armazenamento. Assim, a ferritina contém e mantém os átomos de ferro que poderiam formar agregados de precipitados tóxicos. De acordo com a proporção entre as subunidades de cadeias leves e pesadas, a isoferritina será mais ácida (rica em cadeias pesadas) ou mais básica (rica em cadeias leves). Essas últimas predominam nos tecidos comprometidos com a estocagem do ferro, como fígado e baço, enquanto a forma rica em cadeias pesadas predomina nos tecidos do coração e eritrócitos. ${ }^{2,3}$

A hemossiderina corresponde à forma degradada da ferritina, em que a concha protéica foi parcialmente desintegrada, permitindo que o ferro forme agregados. Pode ser visualizada à microscopia óptica após a coloração com azul da Prússia ou reação de Perl, em que a hemossiderina cora com ferrocianeto de potássio na presença de ácido clorídrico. ${ }^{3}$

\section{Homeostase do ferro}

A homeostase do ferro é regulada por dois mecanismos principais: um deles intracelular, de acordo com a quantidade de ferro que a célula dispõe, e o outro sistêmico, onde a hepcidina tem papel crucial. 


\section{Regulação intracelular}

Para evitar excesso de ferro livre ou falta dele dentro da célula, proteínas reguladoras do ferro (IRP1 e IRP2) controlam a expressão pós-transcricional dos genes moduladores da captação e estoque do ferro. Em condições de baixa quantidade de ferro intracelular, essas proteínas vão se ligar a estruturas em forma de alças presentes nas regiões não codificadoras do mRNA conhecidas como elementos responsivos ao ferro (IRE). Os IRE são seqüências de mRNA constituídas de 30 nucleotídeos altamente conservados que podem estar localizadas nas regiões não codificadoras 3' ou 5'.

Quando os IREs estão localizados na extremidade 3', a ligação com o IRP protege o mRNA da degradação e prossegue a síntese protéica. A ligação do IRP com o IRE localizado na extremidade $5^{\prime}$ inibe a tradução do mRNA em proteína, diminuindo sua síntese. Por outro lado, em condições de excesso de ferro intracelular, as IRP seriam inativas por dois mecanismos distintos: a IRP1 é uma proteína citosólica bifuncional que contém um cluster Fe-S. Na presença de ferro, a IRP1 age como uma aconitase (interconvertendo citrato e isocitrato) e na ausência de ferro liga-se com grande afinidade aos IREs de vários transcriptos da homeostase do ferro. Por outro lado, a IRP2 é inativada por um mecanismo dependente de ferro e nas células repletas de ferro não ocorre a ligação IRP2-IRE. Os elementos IRE localizados próximos à região não codificadora 3', quando não ligados ao IRP permitem que haja a clivagem do mRNA e a síntese protéica é interrompida. A não ligação do IRP aos IRE localizados próximos à região $5^{\prime}$ permite que o complexo de inicialização da tradução seja ativado, induzindo a síntese protéica., ${ }^{3,11,22}$

A DMT-1 e a ferroportina apresentam estruturas "IRElike", embora a função dos IREs nesses transportadores de ferro pareça ser mais complexa e ainda não totalmente esclarecida. Os níveis de mRNA da DMT-1 aumentam significativamente na deficiência de ferro em modelos experimentais, sugerindo que as IREs na região 3' podem mediar a expressão da DMT-1, estabilizando seu transcripto por um mecanismo ferro-dependente, embora não de maneira uniforme, entre as diversas células. A presença de estruturas "IRElike" foi confirmada na região não traduzida 5 ' do mRNA da ferroportina. Estudos sugerem que a regulação de sua expressão ocorra em nível pós-transcricional e é mediada pelo sistema IRE-IRP, embora um mecanismo independente do IRE também participe da regulação da expressão da ferroportina em nível protéico. ${ }^{5}$

\section{Regulação sistêmica}

Normalmente o ferro é eliminado do organismo pelas secreções corpóreas, descamação das células intestinais e epidermais ou sangramento menstrual. O organismo não possui um mecanismo específico para eliminar o excesso de ferro absorvido ou acumulado após a reciclagem do ferro pelos macrófagos. Assim, o controle do equilíbrio do ferro requer uma comunicação entre os locais de absorção, utilização e estoque. Essa comunicação é feita pela hepcidina, um hormônio peptídeo circulante recentemente descrito que teria um papel regulatório fundamental na homeostase do ferro, coordenando o uso e o estoque do ferro com a sua aquisição. Trata-se de um peptídeo antimicrobiano mediador da imunidade inata, principalmente nos vertebrados inferiores. A atividade antimicrobiana é conferida pela propriedade da hepcidina em romper as membranas microbiais e na restrição da disponibilidade de ferro ao desenvolvimento microbiano. ${ }^{25,26}$ Nos vertebrados superiores, a sua atividade está muito mais relacionada à homeostase do ferro. $\mathrm{O}$ papel hormonal da hepcidina foi descoberto em experimentos animais em que camundongos deficientes de hepcidina desenvolviam sobrecarga de ferro, especialmente no fígado, pâncreas e coração e, paradoxalmente, apresentavam depleção de ferro nos macrófagos. Por outro lado, animais que superexpressavam a hepcidina apresentavam anemia microcíticahipocrômica ao nascimento e morriam rapidamente. ${ }^{27}$ Ficou assim estabelecido que a hepcidina seria um regulador negativo do metabolismo do ferro. É sintetizada pelo fígado na forma de um propeptídeo de 84 aminoácidos (aa) e subsequentemente processado e secretado na circulação onde é detectada no plasma e na urina como um peptídeo de 25 aa. Fragmentos de 22 e 20 peptídeos são também encontrados, mas não são biologicamente ativos. ${ }^{28,29}$

Regulam a expressão da hepcidina o estado do ferro (a sobrecarga de ferro aumenta sua expressão, enquanto a anemia e hipoxemia reduzem-na) e o estado inflamatório, em que a IL-6 tem um papel fundamental. ${ }^{30}$ Trabalhos experimentais mostraram que a infusão de IL-6 estimula rapidamente a excreção urinária de hepcidina e induz à hipoferremia. Foi demonstrado que a IL-6 age diretamente nos hepatócitos estimulando a produção de hepcidina. ${ }^{31}$

A ferroportina é o receptor da hepcidina e a interação hepcidina-ferroportina controla os níveis de ferro nos enterócitos, hepatócitos e macrófagos. O complexo hepcidina-ferroportina é internalizado nos domínios da membrana basolateral dos macrófagos e a ferroportina é degradada, bloqueando a liberação do ferro dessas células. ${ }^{32}$ Como conseqüência ocorre o acúmulo de ferro nos hepatócitos e macrófagos. A redução da passagem do ferro para o plasma resulta na baixa saturação da transferrina e menos ferro é liberado para o desenvolvimento do eritroblasto (Figura 3) (revisado em ${ }^{33}$ ).

A ação da hepcidina no processo de absorção intestinal do ferro foi recentemente demonstrada em estudos com culturas de células. A inibição da captação do ferro pelos enterócitos se dá pela inibição da transcrição da DMT-1 induzida pela hepcidina, enquanto os níveis de mRNA e da própria ferroportina nessas células não se alteram. Os autores concluíram que o efeito da hepcidina é célula-dependente, com ações diferenciadas nos macrófagos e nos enterócitos. ${ }^{34}$ 


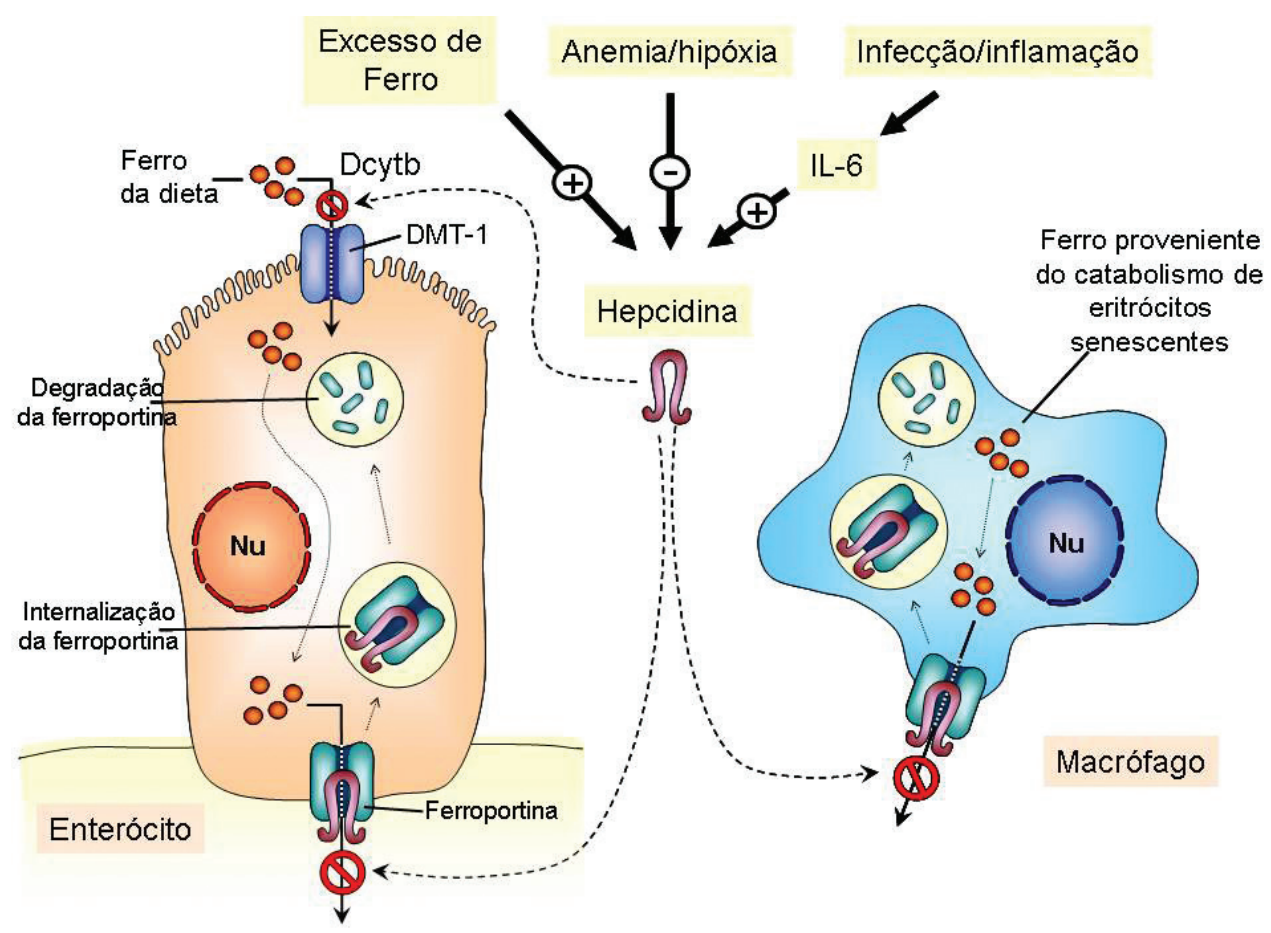

Figura 3. Ação da hepcidina no metabolismo do ferro. Ao formar o complexo com a ferroportina leva à sua degradação. No enterócito, o ferro não é transportado para o exterior da célula, e a absorção é inibida (figura à esquerda). No macrófago, o ferro fica acumulado no seu interior, diminuindo o ferro disponível para a eritropoiese (figura à direita).



Figura 4. Alterações do metabolismo do ferro na ADC. Papel dos mediadores inflamatórios e do sistema imune nos distúrbios do ferro levando à retenção do ferro dentro dos macrófagos e limitando a sua disponibilidade para as células eritróides (baseado em ${ }^{40}$ ) 
A regulação da expressão da hepcidina ocorre em nível transcricional. As citocinas inflamatórias, em especial a IL-6, induzem a transcrição do peptídeo antimicrobial da hepcidina (HAMP) pela ativação do Stat3 e da ligação do Stat3 ao elemento regulatório no promotor do HAMP. ${ }^{35,36} \mathrm{O}$ gene HAMP é também ativado via BMPs (bone morphogenetic proteins), citocinas com importantes funções na regulação da proliferação, diferenciação, apoptose e migração tecidual. A BMP e seus receptores fosforilam proteínas intracelulares conhecidas como RSmad. As RSmads combinam com a Smad4 e esse complexo é deslocado para dentro do núcleo onde ativa a transcrição dos genes-alvo, estimulando a síntese da hepcidina (revisado $\mathrm{em}^{33}$ ). É sugerida também uma menor expressão da Dcytb e DMT-1 induzida pela hepcidina

Em situações de anemia e hipóxia haveria uma inibição da expressão da hepcidina, visando uma maior absorção de ferro pelos enterócitos e maior exportação de ferro do sistema reticuloendotelial e enterócitos aumentando a disponibilidade de ferro para a eritropoiese. Aparentemente, a Tf diférrica tem um papel fundamental nessa regulação. Na superfície celular do hepatócito, a Tf diférrica competiria com a HFE pela ligação à TfR1. Em condições de altas concentrações de Tf diférrica haveria uma maior ligação da Tf ao seu receptor e a HFE livre sinalizaria para o núcleo sintetizar mais hepcidina. Numa situação inversa, com baixa saturação de $\mathrm{Tf}$, a competição para a ligação ao TfR seria vantajosa para a HFE. Uma diminuição nos níveis de HFE livres levaria à redução na expressão da hepcidina mediada pelo HFE. ${ }^{12,37} \mathrm{Como}$ a expressão da hepcidina é regulada também pelas proteínas hemojuvelina (HJV) e TfR2, mutações nessas moléculas e na $\beta 2$ microglobulina, que interagem com a HFE na superfície celular, levam ao fenótipo de hemocromatose, em que a expressão da hepcidina está diminuída ou não responsiva ao excesso de ferro absorvido da dieta. ${ }^{28}$

A hepcidina está particularmente associada à fisiopatogênese da Anemia de Doença Crônica (ADC), definida como uma anemia hipoproliferativa, associada a condições infecciosas, inflamatórias ou neoplásicas e caracterizada, laboratorialmente, por hipoferremia na presença de estoques adequados de ferro. Basicamente, a ADC resulta da ativação dos sistemas imune e inflamatório, o que leva a uma excessiva liberação de citocinas e proteínas de fase-aguda. Como conseqüências teremos: 1. anormalidades no metabolismo e utilização prejudicada do ferro; 2 . produção inadequada e bloqueio da resposta dos progenitores eritróides à eritropoetina; 3 . redução da sobrevida das hemácias; e 4. proliferação e diferenciação alteradas dos progenitores eritróides. ${ }^{11}$ As principais citocinas envolvidas na fisiopatogênese da ADC são: interferon gama, fator de necrose tumoral alfa, IL-1, IL-6 e IL-10. Entre elas. a IL-6 tem um papel fundamental, já que é o principal estimulador da produção de hepcidina pelos hepatócitos. A inibição da absorção do ferro nos enterócitos e o bloqueio de liberação pelos macrófagos vão levar à hipoferremia que, por sua vez, limitará a disponibilida- de de ferro para a eritropoiese e, consequentemente, causa a anemia. (revisado em ${ }^{38,39,40}$ ) (Figura 4).

A identificação de novas proteínas envolvidas com a homeostase do ferro tem auxiliado no entendimento dos diversos distúrbios relacionados tanto à carência como ao acúmulo desse metal essencial. Novos estudos esclarecendo as atividades dessas proteínas e a inter-relação entre elas poderão representar novas perspectivas tanto em termos diagnósticos como terapêuticos.

\begin{abstract}
The perfect synchronism of intestinal absorption, use and storage of iron is critical for maintaining a balance in the organism. Disorders in these processes may lead either to iron deficiency or to iron overload, both of which have important clinical and laboratorial consequences for the patient. This review describes aspects related to iron metabolism and the participation of several proteins and mediators in these mechanisms. Moreover, intracellular and systemic regulation is responsible for providing the optimal iron concentration for cellular metabolism and, in particular, for adequate hematopoiesis. The relationship between hepcidin and acute phase response is presented and how changes in hepcidin expression may be related to the physiopathogenesis of anemia of chronic disease. Rev. Bras. Hematol. Hemoter. 2008;30(5):390-397.
\end{abstract}

Key words: Iron metabolism; iron deficiency anemia; iron overload; hepcidin; anemia of chronic disease

\section{Agradecimento}

Ao Prof. Dr. Ronei Mamoni, brilhante pesquisador e artista, pelas ilustrações dessa revisão.

\section{Referências Bibliográficas}

1. Wijayanti N, Katz N, Immenschuh. Biology of heme in health and disease. Curr Med Chem. 2004;11(8):981-6.

2. Hoffbrand AV, Pettit FE, Moss PAH. Essential Haematology. 5th ed. Oxford (UK): Blackwell Publishing; c2006. Chapter 3, Hypochromic anaemias and iron overload; p. 28-43

3. Fairbanks VG, Beutler E. Iron metabolism. In: Beutler E, Lichtman MA, Coller BS, Kipps TJ, Seligsohn U, editors. WilliamsHematology. $6^{\text {th }}$ ed. New York: Mcgraw-Hill; 2001.p. 295-304.

4. Beaumont $\mathrm{C}$, Vailont $\mathrm{S}$. Iron homeostasis. In: Beaumont $\mathrm{C}$, Beris $\mathrm{P}$, Beuzard Y, Brugnara C, editors. Disorders of iron homeostasis, erythrocytes, erythropoiesis. Genova, Italy: Forum Service Editore; 2006, p.393-406.

5. Donovan A, Roy CN, Andrews NC. The ins and outs of iron homeostasis. Physiology (Bethesda). 2006;21:115-23.

6. Chung J, Wessling-Resnick M. Molecular mechanisms and regulation of iron transport. Crit Rev Clin Lab Sci 2003;40(2):151-82.

7. Andrews NC. A genetic view of iron homeostasis. Semin Hematol. 2002;39(4):227-34

8. Krishnamurthy P, Xie T, Schuetz JD. The role of transporters in cellular heme and porphyrin homeostasis. Pharmacol Ther. 2007; 114(3):345-58. 
9. Pietrangelo A. The ferroportin disease. Blood Cells Mol Dis. 2004; 32(1):131-8.

10. Oates PS. The role of hepcidin and ferroportin in iron absorption. Histol Histopathol. 2007;22(7):791-804.

11. Nairz M, Weiss G. Molecular and clinical aspects of iron homeostasis: From anemia to hemochromatosis. Wien Klin Wochenschr. 2006;118(15-16):442-62.

12. Frazer DM, Anderson GJ. The orchestration of body iron intake: how and where do enterocytes receive their cues? Blood Cells Mol Dis. 2003;30(3):288-97.

13. Knutson M, Wessling-Resnick M. Iron metabolism in the reticuloendothelial system. Crit Rev Biochem Mol Biol. 2003;38 (1):61-88

14. Ponka P, Beaumont C, Richardson DR. Function and regulation of transferrin and ferritin. Semin Hematol. 1998;35(1):35-54.

15. Worwood M. Serum transferrin receptor assays and their application. Ann Clin Biochem. 2002;39(Pt 3):221-30.

16. Baynes RD. Assessment of iron status. Clin Biochem. 1996;29 (3):209-15

17. Ohgami RS, Campagna DR, Greer EL, et al. Identification of a ferrireductase required for efficient transferrin-dependent iron uptake in erythroid cells. Nat Genet. 2005;37(11):1264-9.

18. Beguin Y. The soluble transferrin receptor: biological aspects and clinical usefulness as quantitative measure of erythropoiesis. Haematologica. 1992;77(1):1-10.

19. Skikne BS, Flowers CH, Cook JD. Serum transferrin receptor: a quantitative measure of tissue iron deficiency. Blood. 1990; 75 (9):1870-6

20. Kawabata H, Yang R, Hirama T, Vuong PT, Kawano S, Gombart $\mathrm{AF}$, et al. Molecular cloning of transferrin receptor 2. A new member of the transferrin receptor-like family. J Biol Chem. 1999 Jul 23;274(30):20826-32.

21. Roetto A, Daraio F, Alberti F, Porporato P, Calì A, De Gobbi M, et al. Hemochromatosis due to mutations in transferrin receptor 2 . Blood Cells Mol Dis. 2002;29(3):465-70.

22. Dunn LL, Rahmanto YS, Richardson DR. Iron uptake and metabolism in the new millennium. Trends Cell Biol. 2007;17 (2): 93-100.

23. Cooper JM, Schapira AH. Friedreich's ataxia: coenzyme Q10 and vitamin E therapy. Mitochondrion. 2007;7 (Supp11):S127-35.

24. Alcindor T, Bridges KR. Sideroblastic anaemias. Br J Haematol. 2002;116(4):733-43.

25. Park $\mathrm{CH}$, Valore EV, Waring AJ, Ganz T. Hepcidin, a urinary antimicrobial peptide synthesized in the liver. J Biol Chem. 2001; 276(11):7806-10.

26. Krause A, Neitz S, Mägert HJ, et al. LEAP-1, a novel highly disulfide-bonded human peptide, exhibits antimicrobial activity. FEBS Lett. 2000;480(2-3):147-50

27. Nicolas G, Bennoun M, Porteu A, et al. Severe iron deficiency anemia in transgenic mice expressing liver hepcidin. Proc Nat Acad Sci USA. 2002 Apr 2;99(7):4596-601.

28. Ganz T, Nemeth E. Iron imports. IV. Hepcidin and regulation of body iron metabolism. Am J Physiol Gastrointest Liver Physiol. 2006;290(2):G199-203

29. Ganz T. Hepcidin--a regulator of intestinal iron absorption and iron recycling by macrophages. Best Pract Res Clin Haematol. 2005;18(2):171-82

30. Nemeth E, Rivera S, Gabayan V, Keller C, Taudorf S, Pedersen BK, et al. IL-6 mediates hypoferremia of inflammation by inducing the synthesis of the iron regulatory hormone hepcidin. J Clin Invest. 2004;113(9):1271-6.
31. Rivera S, Liu L, Nemeth E, Gabayan V, Sorensen OE, Ganz T. Hepcidin excess induces the sequestration of iron and exacerbates tumor-associated anemia. Blood. 2005;105(4):1797-802.

32. Nemeth E, Tuttle MS, Powelson J, Vaughn MB, Donovan A, Ward DM et al. Hepcidin regulates cellular iron efflux by binding to ferroportin and inducing its internalization. Science. 2004;306 (5704):2090-3.

33. De Domenico I, Ward DM, Kaplan J. Hepcidin regulation: ironing out the details. J Clin Invest. 2007;117(7):1755-8.

34. Mena NP, Esparza A, Tapia V, Valdes P, Nunez MT. Hepcidin inhibits apical iron uptake in intestinal cells. Am J Physiol Gastrointest Liver Physiol. 2007: DOI 10.1152/ajpgi.00122.2007.

35. Wrighting DM, Andrews NC. Interleukin-6 induces hepcidin expression through STAT3. Blood. 2006;108(9):3204-9.

36. Verga Falzacappa MV, Vujic Spasic M, Kessler R, Stolte J, Hentze $\mathrm{MW}$, et al. STAT3 mediates hepatic hepcidin expression and its inflammatory stimulation. Blood. 2007;109(1):353-8

37. Steele TM, Frazer DM, Anderson GJ. Systemic regulation of intestinal iron absorption. IUBMB Life. 2005;57(7):499-503.

38. Weiss G. Modification of iron regulation by the inflammatory response. Best Pract Res Clin Haematol. 2005;18(2):183-201.

39. Grotto HZW. Anaemia of cancer: an overview of mechanisms involved in its pathogenesis. Med Oncol. 2007, DOI 10.1007/ s12032-007-9000-8.

40. Weiss G. Pathogenesis and treatment of anaemia of chronic disease. Blood Rev. 2002;16(2):87-96.

Avaliação: Editor e dois revisores externos

Conflito de interesse: não declarado

Recebido: 26/11/2007

Aceito após modificações: 17/04/2008 